\title{
Potential Role of OERP as Early Marker of Mild Cognitive Impairment
}

\author{
Sara Invitto ${ }^{1,2,3 *}$, Giulia Piraino ${ }^{3,4}$, Vincenzo Ciccarese ${ }^{4}$, Laura Carmillo ${ }^{5}$, \\ Marcella Caggiula ${ }^{5}$, Giorgio Trianni, ${ }^{3,5}$, Giuseppe Nicolardi ${ }^{1,3}$, Santo Di Nuovo ${ }^{6}$ and \\ Michela Balconi ${ }^{7}$
}

\begin{abstract}
' Human Anatomy and Neuroscience Laboratory, Department of Biological and Environmental Sciences and Technologies, University of Salento, Lecce, Italy, ${ }^{2}$ Microelectronics and Microsystems, Unite of National Research Council, Lecce, Italy, ${ }^{3}$ Laboratory of InterDisciplinary Research Applied to Medicine, Lecce, Italy, ${ }^{4}$ Istituto Santa Chiara, Lecce, Italy, ${ }^{5}$ Neurology Unite, Vito Fazzi Hospital, Lecce, Italy, ${ }^{6}$ University of Catania, Catania, Italy, ${ }^{7}$ Department of Psychology, Università Cattolica del Sacro Cuore, Milan, Italy
\end{abstract}

OPEN ACCESS

Edited by:

Panteleimon Giannakopoulos, Université de Genève, Switzerland

Reviewed by:

Filippo Sean Giorgi,

Azienda Ospedaliero Universitaria

Pisana, Italy

Matteo Cerri,

Università degli Studi di Bologna, Italy

*Correspondence:

Sara Invitto sara.invitto@unisalento.it

Received: 18 May 2018

Accepted: 24 August 2018 Published: 13 September 2018

Citation:

Invitto S, Piraino G, Ciccarese V, Carmillo L, Caggiula M, Trianni G,

Nicolardi G, Di Nuovo S and Balconi M (2018) Potential Role of OERP as Early Marker of Mild Cognitive Impairment. Front. Aging Neurosci. 10:272. doi: 10.3389/fnagi.2018.00272
Olfactory impairment is present in up to $90 \%$ of patients with Alzheimer's disease (AD) and is present in certain cases of mild cognitive impairment (MCl), a transient phase between normal aging and dementia. Subjects affected by $\mathrm{MCl}$ have a higher risk of developing dementia compared to the general population, and studies have found that olfactory deficits could be an indicator of whether such a conversion might happen. Following these assumptions, aim of this study was to investigate olfactory perception in $\mathrm{MCl}$ patients. We recruited $12 \mathrm{MCl}$ subjects (mean age $70 \pm 6.7$ years) through the Alzheimer Assessment Unit (UVA Unite) of ASL Lecce (Italy), and 12 healthy geriatric volunteers (HS) as the control group (mean age $64 \pm 6.0$ years), all of whom were first evaluated via a panel of neuropsychological tests. Subjects were asked to perform an olfactory recognition task involving two scents: rose and eucalyptus, administrated in the context of an oddball task during EEG recordings. Olfactory event-related potential (OERP) components N1 and Late Positive Potential (LPC) were then analyzed as measures of the sensorial and perceptive aspects of the olfactory response, respectively. It was determined that, in the $\mathrm{MCl}$ group, both the $\mathrm{N} 1$ and LPC components were significantly different compared to those of the HS group during the execution of the oddball task. In particular, the N1 amplitude, was reduced, while the LPC amplitude was increased, indicating that a degree of perceptive compensation can occur when sensorial function is impaired. Further, a correlation analysis, involving OERP components and neuropsychological battery scores, indicated that impairment of olfactory perception may share common pathways with impairments of the spatial system and long-term memory processing.

Keywords: CSERP, olfactory perception, $\mathrm{MCI}$, neurodegenerative processes, aging, OERP

\section{INTRODUCTION}

Mild cognitive impairment (MCI) refers to a clinical state marking the transitional phase between normal cognitive function and pathogenic Alzheimer's disease (AD) (Gauthier et al., 2006), characterized by deficits relating to memory, attention span, language, visuospatial ability, the speed of perception, and the performance of executive functions (Saunders and Summers, 2010; Petersen, 2011). Recent literature includes MCI due to AD (Albert et al., 2011) adding also the concept of prodromal AD (Dubois and Albert, 2004; Suk and Shen, 2013; Green et al., 2015), 
and differentiation between amnestic MCI (aMCI), non-amnestic MCI (naMCI) (Dubois and Albert, 2004; Csukly et al., 2016). In aMCI the memory loss is predominant and it is associated with high risk to further conversion to AD (Grundman et al., 2004). Patients with naMCI do not show memory impairment, but do display loss in other cognitive domains and have a higher risk of developing the disease in other dementia forms (e.g., Lewy Body dementia) (Csukly et al., 2016). Both categories can be further assessed to single-domain and multi-domain according to the involvement of one or more cognitive deficit (memory, language, visuospatial ability, speed of mental processing, or executive function) (Libon et al., 2010; Albert et al., 2011). The impairment of neuropsychological and psychophysiological functions can be assessed at behavioral level through neuropsychological tests and can be related with data obtained through different neuroimaging tools (MRI, PET, or SPECT) (Albert et al., 2011). One of these clinical aspects is the atrophy of the hippocampus and the entorhinal cortex, structures involved in the sense of smell (Chételat et al., 2005; Devanand et al., 2007; Shi et al., 2009; Mueller et al., 2010). Clinical studies have shown that olfactory deficits often appear very early in patients at early stages of $\mathrm{AD}$ and/or MCI, often before the manifestation of cognitive symptoms (Masurkar and Devanand, 2014; Roberts et al., 2016). Olfactory impairment is significantly associated with aMCI and may improve the accuracy of the model used fit to predict MCI. Furthermore it is associated with progression from MCI to dementia, and from aMCI to AD (Roberts et al., 2016). So, detection of olfactory impairment could be particularly important when investigating for cue at this neurodegenerative level, given the fact that pathological changes will have already reached the neocortex by the time $\mathrm{AD}$ presents itself at the clinical level (De Santi et al., 2001; Chételat et al., 2005; Roberts et al., 2016). Early detection of AD-related developments in patients with MCI provides a window of opportunity within which disease progression may be delayed or forestalled through lifestyle changes, as well as preventative measures such as enriched environment, memory and cognitive training and neurocognitive enhancement (Hinrichs et al., 2011).

During the $\mathrm{AD}$ progression, a progressive disruption of the cortical association areas, involved in information retrieval, and a reduction of subcortical processing, leads to a rapid loss of neurons and synapses (Tampellini, 2015). Even in the early stages of the disease, there is a sharp decline in cognitive and memory functions. Thus, prodromal AD or MCI due to $\mathrm{AD}$, broadly map onto the pattern of neurofibrillary tangle spreading and is characterized by an atrophy in medial perirhinal cortex, entorhinal cortex and lateral perirhinal cortex (Braak et al., 2006; Krumm et al., 2016), cortical structures closely related to olfactory discrimination (Van Groen and Wyss, 1990; Haberly, 2001; Poellinger et al., 2001; Chapuis et al., 2013). MRI and Fludeoxyglucose-PET (FDG-PET) studies have demonstrated that olfactory performance is significantly reduced in $\mathrm{AD}$ patients compared to control subjects (Wesson et al., 2010; Masurkar and Devanand, 2014). In MCI difference between early and advanced stages, are seen at both functional and anatomical levels due to atrophy in several areas, such as the para-hippocampal gyrus, the medial temporal lobe, the entorhinal cortex of the cingulum, the insula, and the thalamus (Apostolova et al., 2010; Davatzikos et al., 2011), while in AD, atrophy was seen in the entire hippocampus and the neighboring regions, as well as in the temporal lobe, the cingulum, the precuneus, the insular cortex, in the caudate nucleus, and in the frontal cortex (Chételat et al., 2005; Manning et al., 2014).

Olfactory deficits have also been identified in subjects possessing ApoE e4 allele (the best-known genetic risk factor for the development of AD) (Bertram et al., 2007), independent of their current cognitive function (Manning et al., 2014) or their short-term risk of developing AD (Olofsson et al., 2010), which suggests that this gene plays an important role in olfactory identification. It should be noted that gradual anosmia can also occur in healthy elderly subjects (Bahar-Fuchs et al., 2010). Moreover, a study conducted using the University of Pennsylvania Smell Identification Test (UPSIT), a behavioral assessment of olfactory memory, concluded that olfactory deficits may be a useful biomarker of AD progression (Kirkpatrick et al., 2006), while an MRI study of the olfactory bulb and olfactory tract atrophy in MCI and AD patients has indicated that olfactory bulb atrophy could be a surrogate biomarker of AD (Graves et al., 1999). Similarly, while several groups have observed AD-specific neuropathology occurring within the olfactory epithelium (Crino et al., 1995; Masurkar and Devanand, 2014), others, using a different set of markers, have reported seeing the same in the olfactory tissues of healthy and non-AD subjects (Yamagishi et al., 1994). Furthermore, other studies have failed to identify any marker present in the olfactory epithelium that would allow $\mathrm{AD}$ to be reliably distinguished from other conditions, such as Parkinson's disease or vascular dementia (Crino et al., 1995).

While several studies have described changes in event-related potentials (ERP) in MCI (Olichney et al., 2008; van Deursen et al., 2009; Chapman et al., 2011; Laskaris et al., 2013; Green et al., 2015), none so far have evaluated the use of olfactory event-related potentials (OERP) or chemosensory event-related potentials (CSERP) as tools for the investigation of the functional response to controlled chemical stimulation in MCI. We contend that the peculiarities of these ERPs could be exploited to gain a better understanding of the brain areas associated with the processing of various stimuli (e.g., visual, auditory, nociceptive, etc.), and the temporal latencies that are involved. In the present study, we investigate the OERP latencies and amplitudes relating to the sequential activation of different brain areas, starting with the olfactory bulbs, and progressing through the frontal and insular orbital cortex and the middle-rostral regions of the temporal lobe.

Olfactory event-related potentials consist of an early negative N1 component, followed by a positive phase termed $\mathrm{P} 1$, or the Late Positive Component (LPC) (Hummel et al., 1998; Kobal and Hummel, 1998; Pause and Krauel, 2000; Gudziol et al., 2014). When an odoriferous molecule activates the olfactory cells, a negative potential is generated, which is followed by a rebound potential which can be measured by placing electrodes near the olfactory epithelium (Lötsch and Hummel, 2006); the dimension of the track that reproduces the potentials generated change with the variation of the stimulus concentration and shows some 
evidence of the adaptation phenomenon (Pause and Krauel, 2000; Wang et al., 2002).

Usually, during OERP recordings subject had to perform a simple tracking task or a simple olfactory recognition task (Pause et al., 1996; Lötsch and Hummel, 2006; Invitto et al., 2018). The nasal stimulation can be left or right lateralized (Pause et al., 1996) or frontal (with the stimulation of both the nostrils) (Invitto et al., 2018). As usually is for other ERP component early negative component (i.e., N1) is an indicator of the cortical sensorial response, and late components (i.e., LPC) are indicators of the cortical perceptive and cognitive responses to the stimuli. The present research aims to assess if there are changes in OERP that can be correlated with perceptual impairments in MCI patients, and if these changes can be helpful to investigate impaired multi-domain cognitive components.

\section{MATERIALS AND METHODS}

This research was conducted in the Neurology Unit of the Vito Fazzi Hospital (Lecce, Italy). Data collection was performed in accordance with the Code of Ethics of the World Medical Association (Declaration of Helsinki), and written informed consent was obtained from all participants. The study protocol was approved by the Ethical Committee of Vito Fazzi Hospital, Lecce (Report No.01 - 30-01-17).

\section{Subjects}

This study involved 12 geriatric MCI patients and 12 healthy geriatric subjects (HS) recruited between February 2017 and January 2018, matched by age, gender and education. Patients (mean age 70.25 years; $S D \pm 7.74$ ) were enrolled with a clinical suspicion of MCI and admitted to the Alzheimer Assessment Unit (UVA Unite; Lecce, Italy) of the ASL Lecce (Italy), where neuropsychological and olfactory psychophysiological evaluations were conducted. MCI diagnosis was confirmed by neurological and neuropsychological assessment, according to NINCDS-ADRDA (McKhann et al., 1984; Dubois et al., 2007), DSM-V guidelines (American Psychiatric Association, 2013) and according to the latest guidelines and recommendation of National Institute on Aging Alzheimer's Association (NIA-AA) (Albert et al., 2011). According to NIA-AA guidelines our MCI sample can be linked to an intermediated likelihood that MCI syndrome is due to $\mathrm{AD}$. Infact, all patients showed positive biomarkers for neuronal injury (i.e., hippocampal or medial temporal lobe atrophy, diffuse cortical atrophy on MRI and so on). Furthermore, the standard hematochemical tests carried out on these patients, excluded, together with the MRI, the presence of other pathologies and or co-morbidities (Musicco et al., 2004). During the recruitment phase, the patients with other forms or causes of dementia (Babiloni et al., 2016), determined by anamnestic analysis, were excluded from the study.

HS (mean age 66.41 years; $\mathrm{SD} \pm 5.71$ ) were enrolled as volunteers through recruitment notice provided through university students. The HS did not report any current or past psychopathology, neurological illness, or substance abuse and did not report any impairment in normal daily activities.

\section{Neuropsychological Assessment}

Subjects (HS and MCI) were scored through the Mini-Mental State Examination (MMSE), Trial Making Test (TMT), Corsi Test (CT), Digit Span (DS), and Rey Auditory Verbal Learning Test (AVLT) according to NIA-AA guidelines (Albert et al., 2011) and to the guideline of Italian Society of Neurology (Musicco et al., 2004) (see neuropsychological scores in Table 1). Via $t$-tests, it was determined that while the two groups were not appreciably dissimilar in their ages and gender compositions $(p>0.05)$, their MMSE scores were significantly different, as was to be expected $(p<0.05)$.

\section{Olfactory Psychophysiological Assessment}

Subjects performed an olfactory recognition task involving two scents: rose odor perception ( $\beta$-PEA, 2-Phenylethanol, CAS Number: 60-12-8, Number W285803 Sigma-Aldrich) and eucalyptus odor perception (1,3,3-Trimethyl-2-oxabicyclo [2.2.2] octane, CAS Number: 470-82-6, Number C80601 Sigma-Aldrich) chosen according to Hummel et al. (2009). Scents were administered via US2017127971 (A1) 2017-05-11 (Invitto et al., 2014), with $20 \mu \mathrm{L}$ PEA provided in $10 \mathrm{~mL}$ of Vaseline oil, and both odorous solutions were presented in $20 \mathrm{~mL}$ transparent glass vials. Both scents were sealed with plastic film and stored in a darkened cabinet.

The presentation paradigm was an oddball task (Squires et al., 1975) adapted to olfactory stimulation (Invitto et al., 2018). Oddball olfactory task consisted in a pseudorandom administration of different smells (i.e., two different odorants) one of which is the rare stimulus (target stimulus) and the other is the frequent (non-target) stimulus. Usually the percentage of presentation of the rare stimulus is $25 \%$. The presentation of the stimuli is pseudo-randomized so that the subject cannot predict the sequence of stimuli administration. Each stimulation had a duration of $450 \mathrm{~ms}$, with an interstimulus interval (ISI) of $60 \mathrm{~s}$, to avoid olfactory habituation (Pause and Krauel, 2000). The task ended after $40 \mathrm{~min}$.

The device used to record odorous stimuli presentation allows the CSERPs evoked by olfactory stimuli to be measured in a controlled, automated fashion, synchronized to the acquisition of the EEG signal. This method additionally allowed for the blind presentation of smells (Invitto et al., 2014, 2017b).

\section{OERP Recording}

EEG signals were recorded using a 16-channel amplifier (Brain Products V-Amp), mounted on an electrode cap equipped with $\mathrm{Ag} / \mathrm{AgCl}$ electrodes. Brain Vision Recorder and Brain Vision Analyzer (Brain Products $\mathrm{GmbH}$ ) analysis software were used for the OERP study. Electrode impedance was kept below $15 \mathrm{k} \Omega$, and the EEG recording sampling rate was $500 \mathrm{~Hz}$. Electrodes were online referenced to FCz (Luck, 2005), and offline re-referenced with a common offline reference over all electrodes (Luck, 2005). One electrode was placed at the outer canthus of the right eye and used to monitor eye movements. Trials contaminated by eye movements and other artifacts were rejected. The signal was filtered offline $(0.01-50 \mathrm{~Hz}, 24 \mathrm{~dB})$, 
TABLE 1 | MMSE, Rey Auditory Verbal Learning Test (AVLT), Digit Span Test, Corsi Spatial Test, and Trial Making Test (TMT) scores.

\begin{tabular}{|c|c|c|c|c|c|c|c|c|c|c|c|c|}
\hline SUBJ & AGE range & MMSE & AVLTa & AVLTb & AVLTc & Digit Span & Corsi Test & TMT & TMT-B & TMT-AB & ADL & IADL \\
\hline $\mathrm{MCl}$ & $75-80$ & $<22$ & 0 & 0 & 0 & 3 & 1 & 0 & 0 & 0 & 6 & 8 \\
\hline $\mathrm{MCl}$ & $55-60$ & $<22$ & 3 & 3 & 15 & 4 & 4 & 1 & 1 & 1 & 6 & 8 \\
\hline $\mathrm{MCl}$ & $75-80$ & $<22$ & 3 & 4 & 15 & 3 & 3 & 2 & 1 & 4 & 6 & 8 \\
\hline $\mathrm{MCl}$ & $70-75$ & $<22$ & 0 & 0 & 7 & 4 & 4 & 0 & 1 & 2 & 6 & 8 \\
\hline $\mathrm{MCl}$ & $65-70$ & $<22$ & 0 & 0 & 7 & 3 & 3 & 0 & 1 & 4 & 6 & 8 \\
\hline $\mathrm{MCl}$ & $75-80$ & $<22$ & 1 & 1 & 6 & 4 & 3 & 0 & 0 & 1 & 6 & 8 \\
\hline $\mathrm{MCl}$ & $60-65$ & $<22$ & 1 & 0 & 0 & 4 & 2 & 4 & 3 & 3 & 6 & 8 \\
\hline $\mathrm{MCl}$ & $70-75$ & $<22$ & 1 & 0 & 0 & 4 & 1 & 0 & 1 & 4 & 6 & 8 \\
\hline $\mathrm{MCl}$ & $60-65$ & $<22$ & 0 & 2 & 7 & 3 & 4 & 0 & 1 & 4 & 6 & 8 \\
\hline $\mathrm{MCl}$ & $65-70$ & $<22$ & 0 & 0 & 7 & 2 & 2 & 2 & 1 & 1 & 6 & 8 \\
\hline $\mathrm{MCl}$ & $80-85$ & $<22$ & 3 & 3 & 15 & 1 & 4 & 1 & 1 & 1 & 6 & 7 \\
\hline $\mathrm{MCl}$ & $70-75$ & $<22$ & 1 & 0 & 15 & 1 & 1 & 0 & 0 & 0 & 6 & 8 \\
\hline HS & $60-65$ & $>24$ & 25 & 5 & 15 & 6 & 5 & 4 & 4 & 4 & 6 & 8 \\
\hline HS & $65-70$ & $>24$ & 27 & 13 & 15 & 5 & 6 & 4 & 4 & 4 & 6 & 8 \\
\hline HS & $70-75$ & $>24$ & 46 & 11 & 15 & 6 & 4 & 4 & 4 & 4 & 6 & 8 \\
\hline HS & $65-70$ & $>24$ & 50 & 15 & 15 & 7 & 5 & 4 & 4 & 4 & 6 & 8 \\
\hline HS & $75-80$ & $>24$ & 48 & 14 & 15 & 6 & 6 & 4 & 4 & 4 & 6 & 8 \\
\hline HS & $65-70$ & $>24$ & 32 & 15 & 15 & 5 & 5 & 4 & 4 & 4 & 6 & 8 \\
\hline HS & $65-70$ & $>24$ & 30 & 12 & 15 & 6 & 7 & 4 & 4 & 4 & 6 & 8 \\
\hline HS & $70-75$ & $>24$ & 41 & 11 & 15 & 5 & 6 & 4 & 4 & 4 & 6 & 8 \\
\hline HS & $60-65$ & $>24$ & 25 & 15 & 15 & 6 & 7 & 4 & 4 & 4 & 6 & 8 \\
\hline HS & $60-65$ & $>24$ & 21 & 14 & 15 & 5 & 7 & 4 & 4 & 4 & 6 & 8 \\
\hline HS & $55-60$ & $>24$ & 41 & 11 & 15 & 6 & 6 & 4 & 4 & 4 & 6 & 8 \\
\hline HS & $70-75$ & $>24$ & 22 & 12 & 15 & 5 & 5 & 4 & 4 & 4 & 6 & 8 \\
\hline
\end{tabular}

and the threshold for artifact rejection was set at $>|125| \mu \mathrm{V}$ (Pause et al., 1996, 1997). Ocular rejection was performed through independent component analysis (ICA). ERP epochs included a 100 milliseconds pre-stimulus baseline period and a 500 milliseconds post-stimulus segment. Separate averages were calculated for each odorant segmentation (rose and eucalyptus). The detection of peaks was performed as previously described (Invitto et al., 2017a). OERP components were labeled N1 and LPC according to Pause et al. (1996). Latency windows were set to $150-300 \mathrm{~ms}$ for the N1, and 300-500 ms for the LPC (Pause et al., 1996; Pause and Krauel, 2000). These values correspond to the onset of CSERP negative and positive peaks components estimated from grand average waveforms (see Figure 1).

Moreover, we performed a Current Source Density (CSD), a topographic representation of EEG voltage values across the scalp. CSD is the results of mathematical algorithms, in this research conducted through the Brain Vision Analyzer software, that directly transform the scalp-recorded EEG into estimates of radial current flow at scalp. So, in EEG-CSD topography, the positive values identify the direction between the brain source to the scalp, and negative values represent current flow from the scalp to the brain source (Kayser et al., 2010; Kamarajan et al., 2016). To obtain CSD images, grand average OERP waveforms at each electrode were transformed into reference-free CSD estimates using a spherical spline surface Laplacian (interpolation of Spherical Splines - order of Splines 4; Max degree of Legendre Polynomial: 10; Default Lambda 1e-5) (Perrin et al., 1989; Kayser et al., 2010). The number of two representation Maps were chosen in the Interpolation window and the interval between Maps $(\mathrm{ms} / \mathrm{Hz})$ was defined as indicated in the default value (1000). The selected range of maps visualization was set between 100 and $500 \mathrm{~ms}$ (i.e., the temporal range in which the two OERP components were detected).

Then a method comparison operation was carried out in a subtractive way (i.e., differences between different datasets), by subtracting between frequent and infrequent stimulus, to topographically view the generic attentional effect rather than the olfactory oddball task due to the administration of two different odors.

\section{Statistical Analysis}

All statistical analyses were performed using IBM SPSS version 20. Further details regarding statistical tests are described in the following section.

\section{RESULTS}

Shapiro-Wilk and Kolmogorov-Smirnov tests showed that the HS and MCI groups behaved differently from each other with regards to the amplitudes of both the N1 and LPC components. Consequently a separate non-parametric one way ANOVA (i.e., Kruskal-Wallis Test for independent samples) was used for group comparisons (Maris and Oostenveld, 2007). We first analyzed the amplitudes of the N1 components elicited by the rose odorant using the Kruskal-Wallis test. Significant differences 


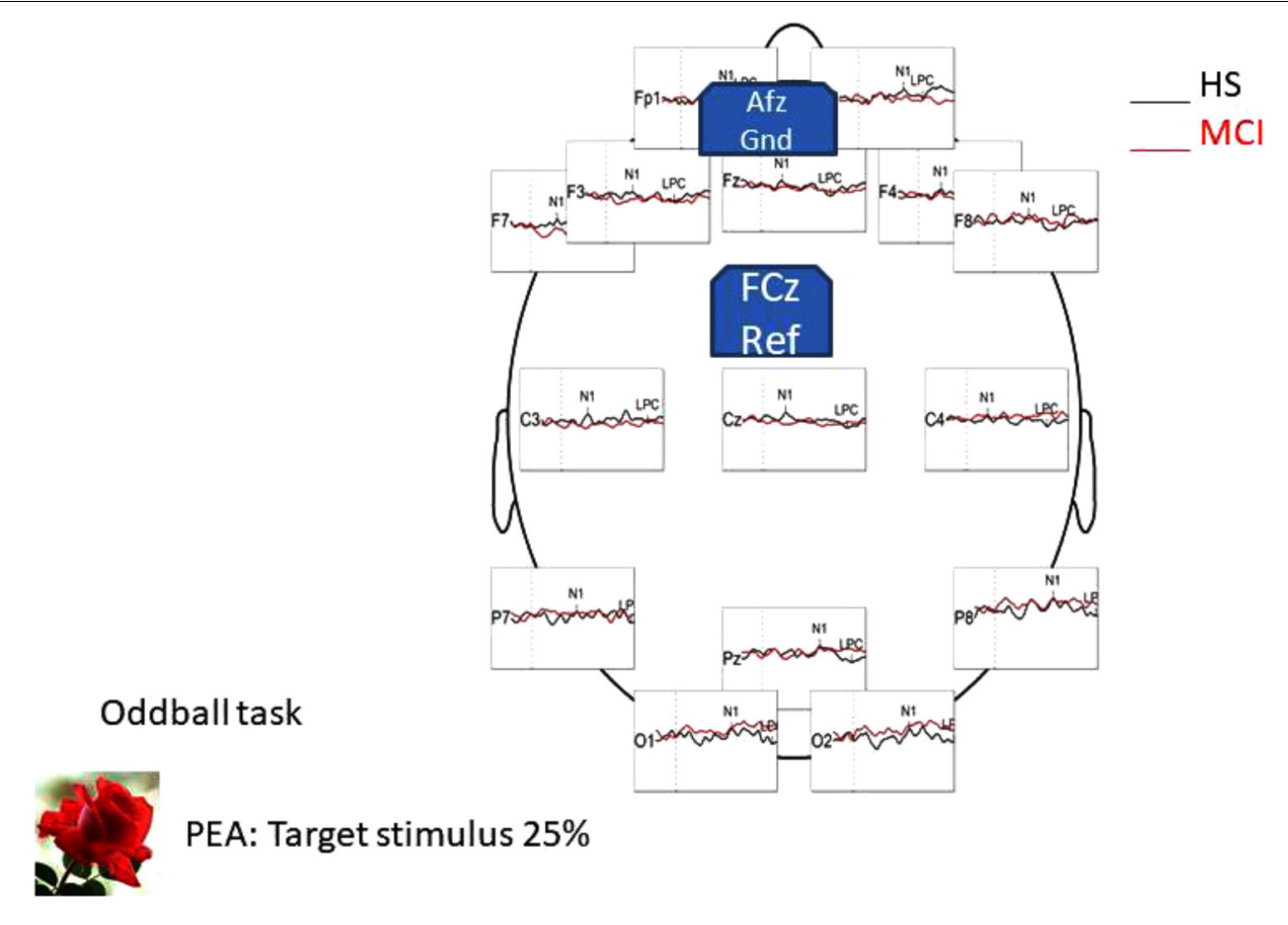

Eucalyptus: Non target stimulus $75 \%$

FIGURE 1 | Head representation illustrating the primary EEG montage used for recording during the oddball task in HS group, with a general comparison of OERP component generated by the PEA (rose odorant) stimulus.

were observed at the F3 position $(z=4.452 ; p=0.03)$, with the MCI group showing decreased N1 amplitudes [MCI mean $=-2.85 \mu \mathrm{V}(\mathrm{SD}=3.39)$ vs. HS mean $=-5.02 \mu \mathrm{V}$ $(\mathrm{SD}=3.13)]$, at F7 $(z=9.200 ; p=0.002)$, where N1 was also smaller in the MCI group [MCI mean $=-2.63 \mu \mathrm{V}(\mathrm{SD}=1.60)$ vs. HS mean $=-6.49 \mu \mathrm{V}(\mathrm{SD}=3.94)]$ (see Figure 2) and at F8 $(z=5.635 ; p=0.018)$, where N1 amplitude was higher in the MCI group [MCI Mean $=-5.72 \mu \mathrm{V}(\mathrm{SD}=3.96)$ vs. HS mean $=-1.96 \mu \mathrm{V}(\mathrm{SD}=3.23)]$. There was, however, no significant difference in the N1 latencies of the two groups. Analysis of LPC amplitudes for the rose odorant identified a significant difference at the F7 $(z=4.278 ; p=0.04)$ and F8 $(z=-4.839 ; p=0.028)$ positions, with the MCI group exhibiting enhanced amplitudes at the former [MCI mean $=8.74 \mu \mathrm{V}$ $(\mathrm{SD}=3.89)$ vs. HS mean $=3.79 \mu \mathrm{V}(\mathrm{SD}=3.89)]$, and decreased amplitudes at the latter [MCI mean $=5.51 \mu \mathrm{V}(\mathrm{SD}=2.50)$ vs. HS mean $=9.72 \mu \mathrm{V}(\mathrm{SD}=4.52)]$ (a comparison of OERP components is shown in Figure 1). The mean amplitudes $( \pm \mathrm{sSD})$ of OERPs elicited by the rose odorant for HS and MCI groups are shown in Table 2.

To investigate overall trends in olfactory perception of frequently encountered stimuli in an oddball setting, we analyzed the OERPs elicited by eucalyptus. The Kruskal-Wallis test for independent samples revealed significant differences in $\mathrm{N} 1$ amplitudes at C4 $(z=7.934 ; p=0.005)$, where values were lower in the MCI group [MCI mean $=-1.45 \mu \mathrm{V}(\mathrm{SD}=0.76)$ compared to $\mathrm{HS}$ mean $=-3.30 \mu \mathrm{V}(\mathrm{SD}=1.75)], \mathrm{F} 7(z=-5.078 ; p=0.024)$ $[\mathrm{MCI}$ mean $=-4.29 \mu \mathrm{V}(\mathrm{SD}=2.40)$ vs. HS mean $=-1.91 \mu \mathrm{V}$ $(\mathrm{SD}=2.15)]$, and in $\mathrm{N} 1$ latencies at Fp2 $(z=5.084 ; p=0.024)$ $[\mathrm{MCI}$ mean $=157 \mathrm{~ms}(\mathrm{SD}=60)$ vs. $\mathrm{HS}=215 \mathrm{~ms}(\mathrm{SD}=45)]$ and F7 $(z=5.081 ; p=0.024)[\mathrm{MCI}$ mean $=211 \mathrm{~ms}(\mathrm{SD}=48)$ vs. HS mean $=162 \mathrm{~ms}(\mathrm{SD}=63)]$. Detailed features of the N1 and the LPC are shown in Table 3, and a comparison of HS and MCI OERPs recorded at the $\mathrm{C} 4$ electrode is shown in Figure 3. Our analysis also indicated that there were no significant differences in the LPC components elicited by the eucalyptus scent.

Figure 4 illustrates the CSD in HS and in MCI groups for the rose odorant, during the N1 and LPC phases. Images show how the two samples allocate the attention differently. In general, the range in voltage is lower in the MCI (MCI $= \pm 2.03 \mu \mathrm{V}$ vs. $\mathrm{HS}= \pm 2.45 \mu \mathrm{V})$ and the negative component seems to be more frontal and lateralized on the left, while the positive component seems more lateralized on the right occipito-temporal region.

The association between the results of the neuropsychological test and the OERP amplitudes that had been found to be significantly different between MCI and HS groups via the analyses described above (i.e., those recorded at F3, F7, and F8 for the N1 component and F7 and F8 for the LPC component) was further investigated via Kendall's tau-b ( $\tau b)$ correlation coefficient analysis, for which detailed values are shown in 


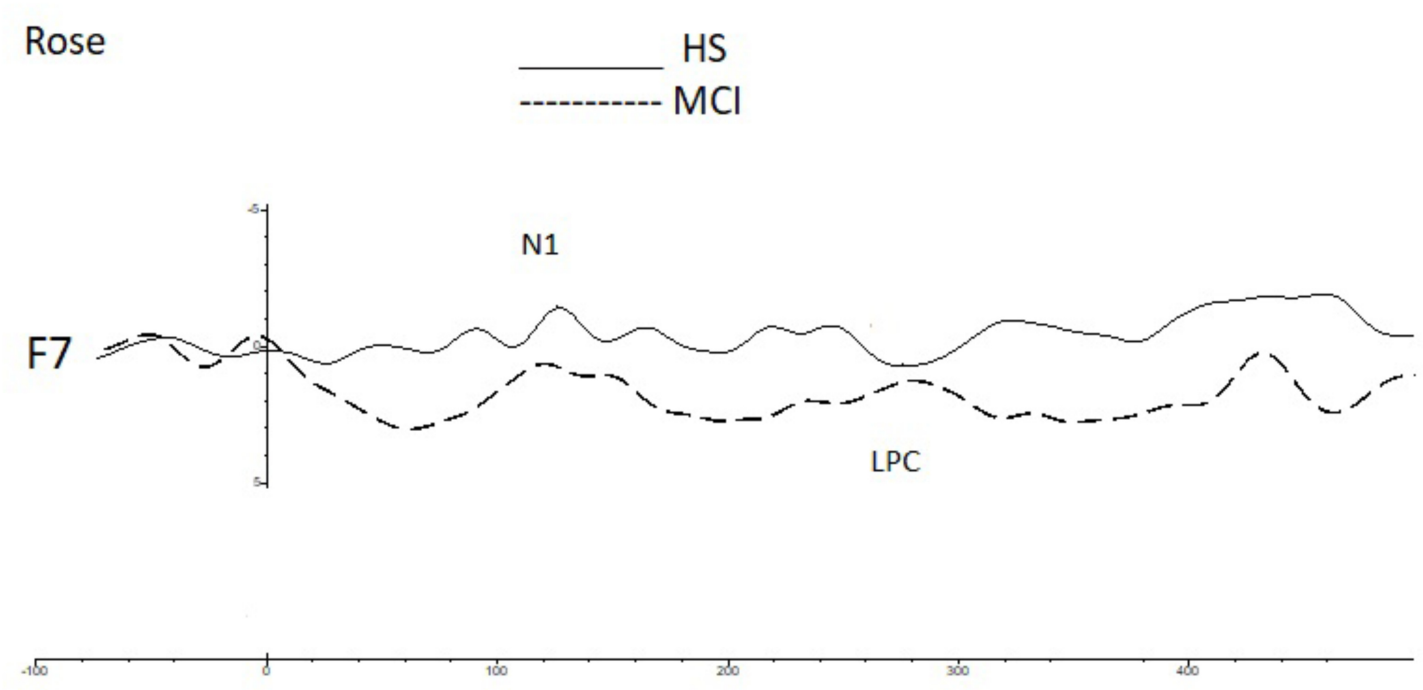

FIGURE 2 | A comparison of the grand averages of OERP waveforms (recorded at the F7 electrode) elicited by the rose odorant for the MCI (dashed line) and HS (continuous line) groups. The N1 and LPC components are labeled.

TABLE 2 | Means of N1 and LPC amplitudes ( $\mu$ V) elicited by the rose odorant for MCl and HS groups.

\begin{tabular}{|c|c|c|c|c|c|c|c|c|c|c|}
\hline \multirow[t]{2}{*}{ Electrode } & \multicolumn{5}{|c|}{ N1 Rose } & \multicolumn{5}{|c|}{ LPC Rose } \\
\hline & \multicolumn{2}{|c|}{ HS } & \multicolumn{3}{|c|}{$\mathrm{MCl}$} & \multicolumn{2}{|c|}{ HS } & \multicolumn{3}{|c|}{$\mathrm{MCl}$} \\
\hline $\mathrm{Fp} 1$ & -5.58 & 6.63 & -3.55 & 4.12 & 0.42 & 3.91 & 6.29 & 5.54 & 2.45 & 0.53 \\
\hline $\mathrm{Fp} 2$ & -5.12 & 7.24 & -4.11 & 2.83 & 0.60 & 5.31 & 6.66 & 4.75 & 2.67 & 0.77 \\
\hline C3 & -4.29 & 3.58 & -2.47 & 1.88 & 0.29 & 2.69 & 3.43 & 4.05 & 3.49 & 0.77 \\
\hline $\mathrm{C} 4$ & -3.34 & 2.35 & -4.56 & 3.41 & 0.74 & 3.55 & 3.03 & 3.00 & 2.89 & 0.58 \\
\hline P7 & -6.22 & 5.59 & -5.04 & 3.01 & 0.64 & 6.23 & 3.69 & 6.25 & 2.60 & 0.77 \\
\hline P8 & -6.45 & 3.73 & -4.95 & 3.84 & 0.26 & 6.74 & 5.09 & 5.70 & 3.30 & 0.20 \\
\hline $\mathrm{O} 1$ & -6.24 & 4.92 & -6.42 & 2.99 & 1.00 & 5.67 & 3.69 & 5.12 & 3.38 & 0.87 \\
\hline $\mathrm{Pz}$ & -3.74 & 3.44 & -3.60 & 1.98 & 0.64 & 4.01 & 3.00 & 4.61 & 2.91 & 0.92 \\
\hline $\mathrm{Fz}$ & -2.48 & 1.99 & -2.36 & 2.91 & 0.94 & 4.77 & 3.87 & 3.97 & 2.64 & 0.72 \\
\hline
\end{tabular}

SD, standard deviation; $p, p$-value.

Table 4. A negative correlation between the N1 amplitudes of F7 and F3 was seen. Additionally, F7 N1 amplitude was found to be positively correlated with high neuropsychological test scores, and an association between the CORSI and TMTs was also seen (A-B-AB). Moreover, OERP amplitudes were found to be related to spatial scores. While left frontotemporal components were determined to be negatively correlated with high scores in spatial memory tasks, right frontotemporal components were, by contrast, positively correlated with the same. Finally, we also observed that subject scores for the Rey AVLT, which tests for episodic declarative memory, are particularly highly correlated with scores achieved in the b version of the test, designed to evaluate long-term episodic memory.

\section{DISCUSSION AND CONCLUSION}

Olfaction can serve as a useful biomarker in processes such as $\mathrm{AD}$ and Parkinson's disease, as it is often the first sense to be affected by neurodegeneration. It is additionally known that subjects afflicted with MCI and/or who possess the e4 allele 
TABLE 3 | Means of N1 and LPC amplitudes $(\mu \mathrm{V})$ elicited by the eucalyptus odorant for $\mathrm{MCl}$ and HS groups.

\begin{tabular}{|c|c|c|c|c|c|c|c|c|c|c|}
\hline \multirow[t]{3}{*}{ Electrode } & \multicolumn{5}{|c|}{ N1 eucalyptus } & \multicolumn{5}{|c|}{ LPC eucalyptus } \\
\hline & \multicolumn{2}{|c|}{ HS } & \multicolumn{3}{|c|}{$\mathrm{MCl}$} & \multicolumn{2}{|c|}{ HS } & \multicolumn{3}{|c|}{$\mathrm{MCl}$} \\
\hline & Mean & $S D$ & Mean & $S D$ & $p$ & Mean & $S D$ & Mean & $S D$ & $p$ \\
\hline Fp1 & -3.58 & 4.36 & -2.82 & 2.41 & 0.89 & 3.21 & 4.47 & 3.45 & 2.84 & 0.57 \\
\hline Fp2 & -4.49 & 4.85 & -2.44 & 3.01 & 0.14 & 3.15 & 3.38 & 3.72 & 2.12 & 0.62 \\
\hline F3 & -2.43 & 1.71 & -3.56 & 1.46 & 0.14 & 3.45 & 2.26 & 2.53 & 1.15 & 0.57 \\
\hline $\mathrm{F} 4$ & -2.98 & 1.07 & -1.87 & 1.52 & 0.91 & 2.76 & 1.86 & 4.52 & 2.53 & 0.12 \\
\hline C3 & -2.13 & 0.91 & -2.61 & 1.11 & 0.26 & 2.17 & 1.16 & 2.22 & 0.96 & 0.72 \\
\hline $\mathrm{C} 4$ & -3.30 & 1.75 & -1.45 & 0.76 & $0.00^{*}$ & 1.97 & 1.45 & 2.76 & 1.87 & 0.29 \\
\hline P7 & -2.90 & 2.76 & -3.83 & 1.90 & 0.44 & 5.24 & 2.95 & 3.37 & 2.23 & 0.18 \\
\hline P8 & -3.64 & 3.46 & -2.99 & 1.86 & 0.78 & 2.89 & 3.16 & 4.47 & 3.25 & 0.26 \\
\hline O1 & -3.11 & 3.27 & -5.60 & 2.98 & 0.08 & 5.50 & 4.49 & 4.30 & 5.41 & 0.48 \\
\hline $\mathrm{O} 2$ & -3.45 & 3.52 & -4.61 & 3.07 & 0.53 & 4.46 & 3.83 & 5.18 & 3.86 & 0.67 \\
\hline F7 & -1.91 & 2.15 & -4.29 & 2.41 & $0.02 *$ & 4.35 & 3.19 & 3.17 & 2.83 & 0.52 \\
\hline F8 & -3.17 & 2.07 & -2.72 & 3.18 & 0.48 & 4.01 & 2.41 & 5.15 & 2.16 & 0.12 \\
\hline $\mathrm{Cz}$ & -2.37 & 0.91 & -1.66 & 1.31 & 0.16 & 2.37 & 1.15 & 2.83 & 1.81 & 0.52 \\
\hline $\mathrm{Pz}$ & -2.03 & 1.96 & -2.83 & 1.48 & 0.08 & 3.55 & 2.22 & 3.18 & 2.54 & 0.29 \\
\hline $\mathrm{Fz}$ & -2.82 & 2.78 & -2.31 & 1.88 & 0.89 & 2.67 & 2.11 & 2.89 & 1.82 & 0.94 \\
\hline
\end{tabular}

$S D$, standard deviation; $p, p$-value.

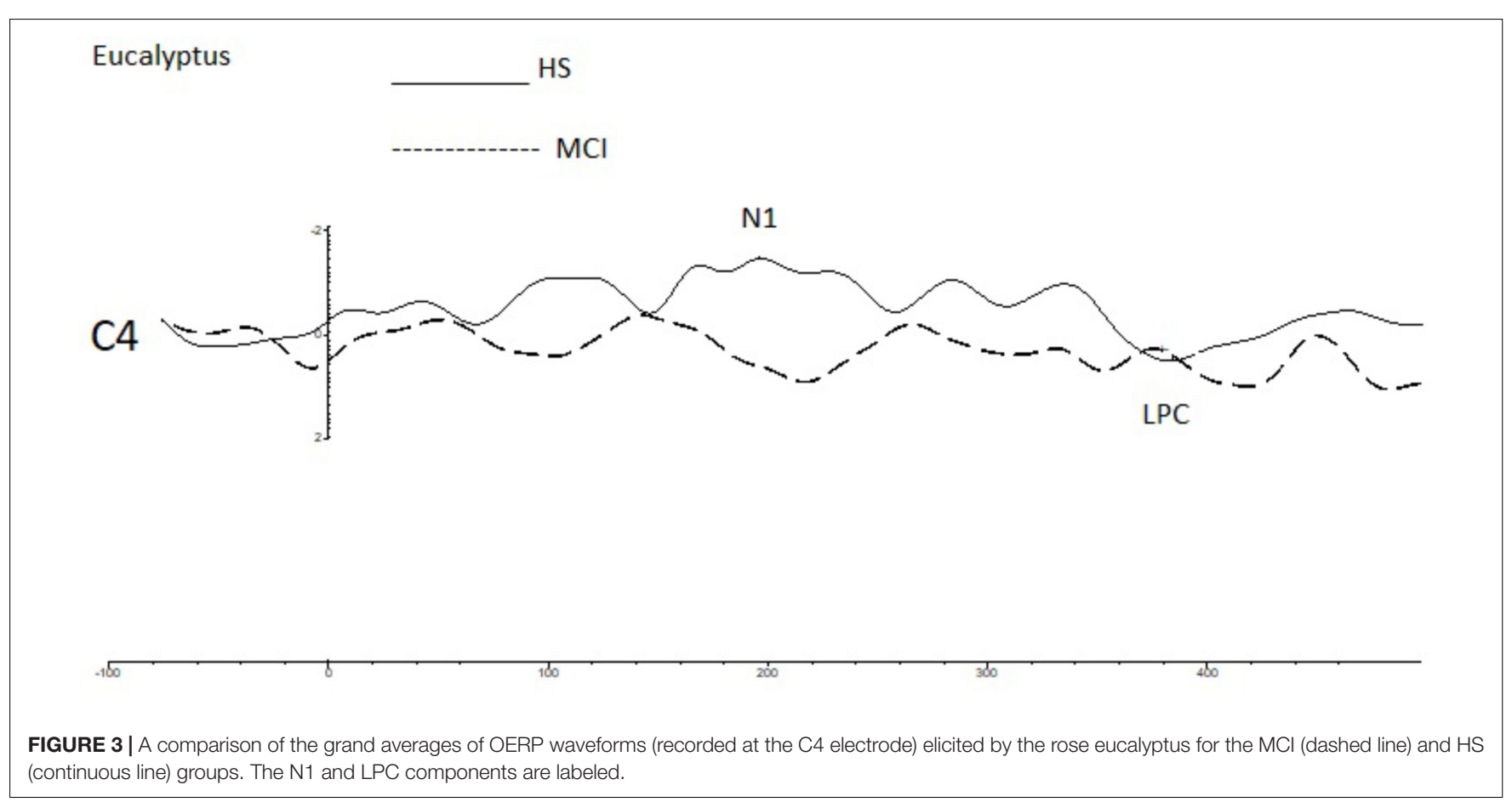

of the ApoE gene, which has been linked to an increased risk for the development of $\mathrm{AD}$, have severe anosmia (Olofsson et al., 2010). Further, MRI studies have suggested that the olfactory bulb is impaired in patients with MCI and AD (Wesson et al., 2010). Finally, several groups have described changes in ERP in MCI (Olichney et al., 2008; van Deursen et al., 2009; Chapman et al., 2011; Laskaris et al., 2013; Green et al., 2015). However, studies relating to OERPs in MCI or AD are currently lacking.
Compared to techniques such as MRI or fMRI, OERP measurements also have a higher temporal resolution, and can be conducted at lower cost with a lower degree of invasiveness. We have, for these reasons, developed a research protocol designed to assess both the sensorial and perceptual aspects of the olfactory cortical response in MCI patients (i.e., sample with intermediate probability that $\mathrm{MCI}$ is due to $\mathrm{AD}$ ). In this study, we evaluated various facets of both the early (N1) and slow potentials (LPC) of the OERP in MCI patients and HS to determine if significant 


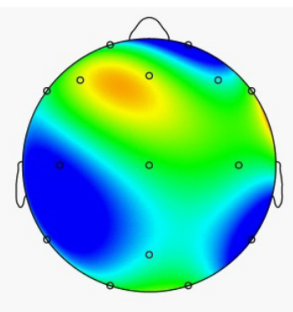

$100 \mathrm{~ms}-300 \mathrm{~ms}$

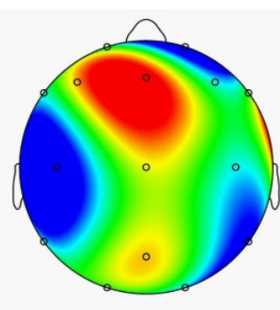

$300 \mathrm{~ms}-500 \mathrm{~ms}$

HS - Rose

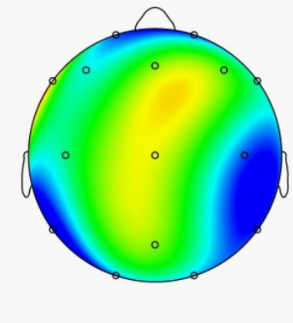

$100 \mathrm{~ms}-300 \mathrm{~ms}$

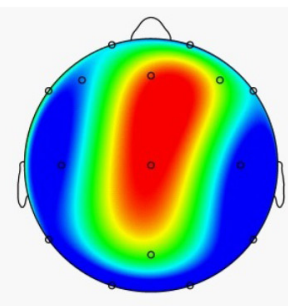

$300 \mathrm{~ms}-500 \mathrm{~ms}$

FIGURE 4 | Topographical map of current source density in the N1 and LPC intervals in the HS and MCI group when presented with the rose odorant.

TABLE 4 | Kendall's tau-b correlation coefficients relating neuropsychological test scores and OERP amplitudes significantly affected in the MCl group (F3, $F 7$, and F8 in N1 component and F7 and F8 in LPC component).

\section{KENDALL'S TAU-B}

\begin{tabular}{|c|c|c|c|c|c|c|c|c|c|c|}
\hline & \multicolumn{2}{|c|}{ F3 (N1) } & \multicolumn{2}{|c|}{ F7 (N1) } & \multicolumn{2}{|c|}{ F8 (N1) } & \multicolumn{2}{|c|}{ F7 (LPC) } & \multicolumn{2}{|c|}{ F8 (LPC) } \\
\hline & Cor. & $p$ & Cor. & $p$ & Cor. & $p$ & Cor. & $p$ & Cor. & $p$ \\
\hline AVLTa & -0.21 & 0.20 & -0.33 & $0.05^{*}$ & 0.31 & 0.06 & -0.17 & 0.29 & 0.25 & 0.13 \\
\hline AVLTb & -0.34 & $0.05^{*}$ & -0.54 & $0.00 * *$ & 0.44 & $0.01 *$ & -0.40 & $0.02 *$ & 0.38 & $0.03^{*}$ \\
\hline AVLTc & -0.32 & $0.05^{*}$ & -0.33 & $0.04^{*}$ & 0.19 & 0.26 & -0.26 & 0.11 & 0.35 & $0.03^{*}$ \\
\hline TMT & -0.33 & 0.06 & -0.52 & $0.00^{* *}$ & 0.31 & 0.09 & -0.29 & 0.10 & 0.40 & 0.02 \\
\hline TMT-B & -0.33 & $0.05^{*}$ & -0.52 & $0.00 * *$ & 0.36 & $0.04 *$ & -0.41 & 0.02 & 0.43 & $0.01 *$ \\
\hline TMT-AB & -0.26 & 0.13 & -0.40 & $0.02^{*}$ & 0.36 & $0.04^{*}$ & -0.45 & $0.01^{* *}$ & 0.29 & 0.10 \\
\hline
\end{tabular}
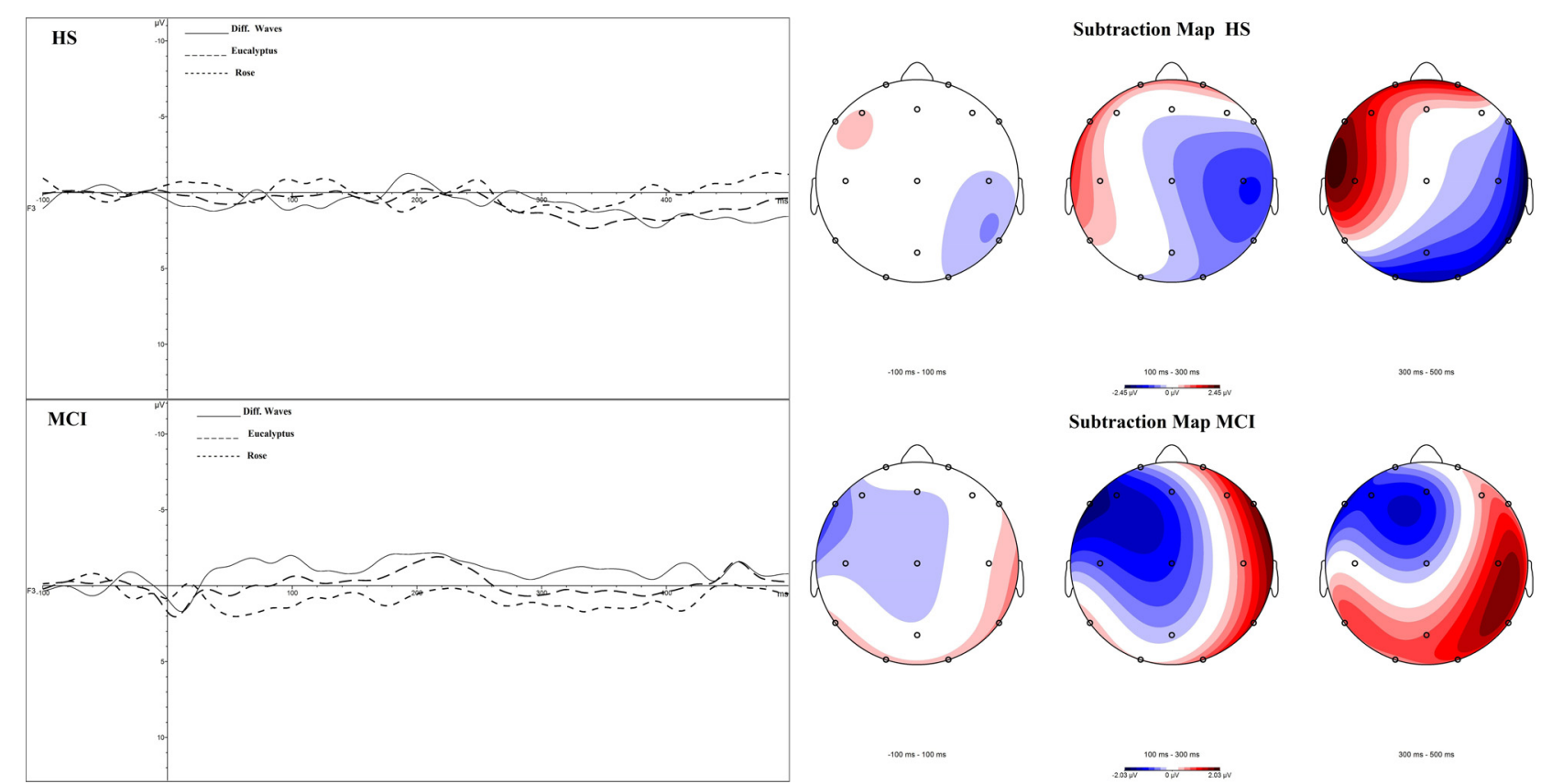

FIGURE 5 | Subtraction OERP components and Map in HS and MCl patients. 
differences exist between the two groups (Figure 5). Our results showed a clear deficit in the early sensory $\mathrm{N} 1$ component in the MCI group, which exhibited reduced amplitudes in the left frontal and right centroparietal lobes compared with healthy controls, which may indicate reduced olfactory discrimination. Topographic mapping of OERP intensities across the scalp showed that the negative components are more compromised in the left orbitofrontal and frontotemporal areas and in the right centroparietal area, which are particularly closely associated with olfactory OERPs (Schriever et al., 2014). Also, slow positive potentials in the left prefrontal cortex in the MCI group had greater amplitudes, and longer latencies. This brain area is involved in olfactory perception and memory, and is specifically activated during the administration of pleasant scents (Soudry et al., 2011). The increased amplitude could be a mechanism compensating for impairments in the olfactory-sensorial components (i.e., N1), indicating the existence of a feedback system capable of activating more arousing resources to better detect the olfactory stimulus (e.g., LPC could be a component that can covert cognitive resources).

A similar mechanism was observed in a previous study involving obstructive sleep apnea syndrome (Invitto et al., 2018). However, the greater activation of early OERP components in the right frontoparietal area and the reduction of LPC in MCI patients seen here can be extremely important in supporting the previous results. Studies have demonstrated that the right frontotemporal area is responsible for the recruitment of olfactory memory rather than its sensorial perception. Also this activation can be the consequence of a compensation of a sensory deficit which, to be efficient, relies on more mnestic than perceptive components (Jones-Gotman and Zatorre, 1993). Further specifications can be due to the correlation between neuropsychological test and OERP results. The best area that fit with olfactory responses and neuropsychological scores is the left frontotemporal area (high scores to neuropsychological tests are related with greater negative amplitude in N1). This area is strongly associated with odor discrimination (Rami et al., 2007). Another interesting result from this study is the correlation between CORSI and TMT scores. OERP amplitudes are related to spatial scores. Left frontotemporal components have negative correlations with high scores in spatial memory tasks, whereas, right frontotemporal components have a positive correlation. These observations support the existing paradigm that the spatial and olfactory systems are closely associated at the level of the cortical pathways (Jacobs et al., 2015). The Rey AVLT, a test for episodic declarative memory, is highly correlated, in particular, the scores of the section linked to long-term episodic memory.

Our data demonstrate the usefulness of OERPs in the study of the early stages of neurodegenerative processes, as there was a clear defect in olfactory function in MCI patients, confirming the findings of others. One particular area that still needs further investigation is to clarify the extent that MCI samples are caused by AD. In fact, our sample was not recruited after genetic or CSF diagnosis, which would confirm $\mathrm{AD}$ pathology underlying the disease or the prodromal $\mathrm{AD}$
(Dubois and Albert, 2004). On the other hand, this study also did reveal the existence of compensatory processes that are activated to balance these deficits during the early stages of multi-domain aMCI, involving not only the sensory system, but also the spatial system. This process seems linked to the recognition process through long-term memory, which, in the specifics of olfactory perception, seems to be activated to recognize the odors no longer through its sensorial components, but through long-term recognition features. We intend to further develop this research by reassessing the same functions within the same cohort of subjects, over the next year, in order to determine if MCI has developed into AD in any of the cases. Our follow up will be conducted after adequate tests assessment, including neuroimaging, biomarkers and genetic assessment of ApoE gene. So we will examine how the olfactory components have been affected by the neurodegenerative process. This will allow us to understand whether these electrophysiological findings found in the multimodal amnesic MCI (with intermediate probability that $\mathrm{MCI}$ is due to $\mathrm{AD}$ ) remain constant or progress; we will also understand if the subjects enter a diagnostic phase of MCI due to $\mathrm{AD}$ or we may actually find direct evidence in $\mathrm{AD}$.

In any case, the electrophysiological data produced by olfactory stimulation shows us that in MCI there are complex alterations that also provide compensatory mechanisms with respect to the physiological responses of geriatric control subjects. These compensatory mechanisms can be considered as further cues in a diagnostic border picture, such as that of MCI with intermediate connection to $\mathrm{AD}$, which shows altered responses on various levels. The assessment of a low-cost, relatively fast and non-invasive test such as that of OERPs may be an additional data to be integrated into this particular diagnostic frame.

\section{AUTHOR CONTRIBUTIONS}

SI contributed to research conception, protocol design, subjects EEG recording, EEG and neuropsychological data analysis, paper writing, and paper review. GP Neuropsychological Tests Administration and scoring. MC, LC, and GN MCI assessment and recruitment. VC technical support to olfactometer. GT Head of Neurology Unite - supervision on patients assessment and recruitment. SDN neuropsychological scoring analysis. $\mathrm{MB}$ theoretical suggestions in the paper review.

\section{FUNDING}

This work was supported by CUIS - 2015 and by 5 x 1000 University of Salento.

\section{ACKNOWLEDGMENTS}

I would like to express my very great appreciation to Prof. Francesco di Russo and Prof. David Mark Katan for the valuable and constructive suggestions given in this research work. 


\section{REFERENCES}

Albert, M. S., DeKosky, S. T., Dickson, D., Dubois, B., Feldman, H. H., Fox, N. C., et al. (2011). The diagnosis of mild cognitive impairment due to Alzheimer's disease: recommendations from the National Institute on Aging-Alzheimer's Association workgroups on. Alzheimers Dement. 7, 270-279. doi: 10.1016/j.jalz. 2011.03.008

American Psychiatric Association (ed.). (2013). "Cautionary statement for forensic use of DSM-5," in Diagnostic and Statistical Manual of Mental Disorders, 5th Edn, (Washington, DC: American Psychiatric Association). doi: 10.1176/appi. books.9780890425596.744053

Apostolova, L. G., Thompson, P. M., Green, A. E., Hwang, K. S., Zoumalan, C., Jack, C. R., et al. (2010). 3D comparison of low, intermediate, and advanced hippocampal atrophy in MCI. Hum. Brain Mapp. 31, 786-797. doi: 10.1002/ hbm. 21148

Babiloni, C., Triggiani, A. I., Lizio, R., Cordone, S., Tattoli, G., Bevilacqua, V., et al. (2016). Classification of single normal and Alzheimer's disease individuals from cortical sources of resting state EEG rhythms. Front. Neurosci. 10:47. doi: 10.3389/fnins.2016.00047

Bahar-Fuchs, A., Chetelat, G., Villemagne, V. L., Moss, S., Pike, K., Masters, C. L., et al. (2010). Olfactory deficits and amyloid-beta burden in Alzheimer's disease, mild cognitive impairment, and healthy aging: a PiB PET study. J. Alzheimers Dis. 22, 1081-1087. doi: 10.3233/JAD-2010-100696

Bertram, L., McQueen, M. B., Mullin, K., Blacker, D., and Tanzi, R. E. (2007). Systematic meta-analyses of Alzheimer disease genetic association studies: the AlzGene database. Nat. Genet. 39, 17-23. doi: 10.1038/ng1934

Braak, H., Alafuzoff, I., Arzberger, T., Kretzschmar, H., and Tredici, K. (2006). Staging of Alzheimer disease-associated neurofibrillary pathology using paraffin sections and immunocytochemistry. Acta Neuropathol. 112, 389-404. doi: 10. 1007/s00401-006-0127-z

Chapman, R. M., McCrary, J. W., Gardner, M. N., Sandoval, T. C., Guillily, M. D., Reilly, L. A., et al. (2011). Brain ERP components predict which individuals progress to Alzheimer's disease and which do not. Neurobiol. Aging 32, 1742-1755. doi: 10.1016/j.neurobiolaging.2009.11.010

Chapuis, J., Cohen, Y., He, X., Zhang, Z., Jin, S., Xu, F., et al. (2013). Lateral entorhinal modulation of piriform cortical activity and fine odor discrimination. J. Neurosci. 33, 13449-13459. doi: 10.1523/JNEUROSCI.138713.2013

Chételat, G., Landeau, B., Eustache, F., Mézenge, F., Viader, F., De La Sayette, V., et al. (2005). Using voxel-based morphometry to map the structural changes associated with rapid conversion in MCI: a longitudinal MRI study. Neuroimage 27, 934-946. doi: 10.1016/j.neuroimage.2005.05.015

Crino, P. B., Martin, J. A., Hill, W. D., Greenberg, B., Lee, V. M.-Y., and Trojanowski, J. Q. (1995). $\beta$-Amyloid peptide and amyloid precursor proteins in olfactory mucosa of patients with Alzheimer's disease, Parkinson's disease, and Down syndrome. Ann. Otol. Rhinol. Laryngol. 104, 655-661. doi: 10.1177/ 000348949510400812

Csukly, G., Sirály, E., Fodor, Z., Horváth, A., Salacz, P., Hidasi, Z., et al. (2016). The differentiation of amnestic type MCI from the non-amnestic types by structural MRI. Front. Aging Neurosci. 8:52. doi: 10.3389/fnagi.2016.00052

Davatzikos, C., Bhatt, P., Shaw, L. M., Batmanghelich, K. N., and Trojanowski, J. Q. (2011). Prediction of MCI to AD conversion, via MRI, CSF biomarkers, and pattern classification. Neurobiol. Aging 32, 2322.e19-2322.e27. doi: 10.1016/j. neurobiolaging.2010.05.023

De Santi, S., De Leon, M. J., Rusinek, H., Convit, A., Tarshish, C. Y., Roche, A., et al. (2001). Hippocampal formation glucose metabolism and volume losses in MCI and AD. Neurobiol. Aging 22, 529-539. doi: 10.1016/S0197-4580(01) 00230-5

Devanand, D. P., Pradhaban, G., Liu, X., Khandji, A., De Santi, S., Segal, S., et al. (2007). Hippocampal and entorhinal atrophy in mild cognitive impairment: prediction of Alzheimer disease. Neurology 68, 828-836. doi: 10.1212/01.wnl. 0000256697.20968.d7

Dubois, B., and Albert, M. L. (2004). Amnestic MCI or prodromal Alzheimer's disease? Lancet Neurol. 3, 246-248. doi: 10.1016/S1474-4422(04)00710-0

Dubois, B., Feldman, H. H., Jacova, C., DeKosky, S. T., Barberger-Gateau, P., Cummings, J., et al. (2007). Research criteria for the diagnosis of Alzheimer's disease: revising the NINCDS-ADRDA criteria. Lancet Neurol. 6, 734-746. doi: $10.1016 /$ S1474-4422(07)70178-3
Gauthier, S., Reisberg, B., Zaudig, M., Petersen, R. C., Ritchie, K., Broich, K., et al. (2006). Mild cognitive impairment. Lancet 367, 1262-1270. doi: 10.1016/S01406736(06)68542-5

Graves, A. B., Bowen, J. D., Rajaram, L., McCormick, W. C., McCurry, S. M., Schellenberg, G. D., et al. (1999). Impaired olfaction as a marker for cognitive decline: interaction with apolipoprotein E epsilon4 status. Neurology 53, 1480-1487. doi: 10.1212/WNL.53.7.1480

Green, D. L., Payne, L., Polikar, R., Moberg, P. J., Wolk, D. A., and Kounios, J. (2015). P50: a candidate ERP biomarker of prodromal Alzheimer's disease. Brain Res. 1624, 390-397. doi: 10.1016/j.brainres.2015.07.054

Grundman, M., Petersen, R. C., Ferris, S. H., Thomas, R. G., Aisen, P. S., Bennett, D. A., et al. (2004). Mild cognitive impairment can be distinguished from alzheimer disease and normal aging for clinical trials. Arch. Neurol. 61, 59-66. doi: 10.1001/archneur.61.1.59

Gudziol, H., Fischer, J., Bitter, T., and Guntinas-Lichius, O. (2014). Chemosensory event-related brain potentials (CSERP) after strictly monorhinal stimulation. Int. J. Psychophysiol. 93, 305-310. doi: 10.1016/j.ijpsycho.2014.06.009

Haberly, L. B. (2001). Parallel-distributed processing in olfactory cortex: new insights from morphological and physiological analysis of neuronal circuitry. Chem. Senses 26, 551-576. doi: 10.1093/chemse/26.5.551

Hinrichs, C., Singh, V., Xu, G., and Johnson, S. C. (2011). Predictive markers for $\mathrm{AD}$ in a multi-modality framework: an analysis of MCI progression in the ADNI population. Neuroimage 55, 574-589. doi: 10.1016/j.neuroimage.2010. 10.081

Hummel, T., Barz, S., Pauli, E., and Kobal, G. (1998). Chemosensory eventrelated potentials change with age. Electroencephalogr. Clin. Neurophysiol. 108, 208-217. doi: 10.1016/S0168-5597(97)00074-9

Hummel, T., Rissom, K., Reden, J., Hähner, A., Weidenbecher, M., and Hüttenbrink, K.-B. (2009). Effects of olfactory Training in patients with olfactory loss. Laryngoscope 119, 496-499. doi: 10.1002/lary.20101

Invitto, S., Calcagnì, A., Mignozzi, A., Scardino, R., Piraino, G., Turchi, D., et al. (2017a). Face recognition, musical appraisal, and emotional crossmodal bias. Front. Behav. Neurosci. 11:144. doi: 10.3389/fnbeh.2017.00144

Invitto, S., Piraino, G., Mignozzi, A., Capone, S., Montagna, G., Siciliano, P. A., et al. (2017b). "Smell and meaning: an OERP study," in Multidisciplinary Approaches to Neural Computing. Smart Innovation, Systems and Technologies, Vol. 69, eds A. Esposito, M. Faudez-Zanuy, F. Morabito, and E. Pasero (Cham: Springer), doi: 10.1007/978-3-319-56904-8_28

Invitto, S., Calcagnì, A., Piraino, G., Ciccarese, V., Balconi, M., De Tommaso, M., et al. (2018). Obstructive sleep apnea syndrome and olfactory perception: an OERP study. Respir. Physiol. Neurobiol. doi: 10.1016/j.resp.2018.07.002 [Epub ahead of print].

Invitto, S., Capone, S., Montagna, G., and Siciliano, P. A. (2014). MI2014A001344 method and system for measuring physiological parameters of a subject undergoing an olfactory stimulation. U.S. Patent No. 20170127971A1. Rome: Universita del Salento.

Jacobs, L. F., Arter, J., Cook, A., and Sulloway, F. J. (2015). Olfactory orientation and navigation in humans. PLoS One 10:e0129387. doi: 10.1371/journal.pone. 0129387

Jones-Gotman, M., and Zatorre, R. J. (1993). Odor recognition memory in humans: role of right temporal and orbitofrontal regions. Brain Cogn. 22, 182-198. doi: 10.1006/brcg.1993.1033

Kamarajan, C., Pandey, A. K., Chorlian, D. B., Porjesz, B., and Begleiter, H. (2016). The use of current source density as electrophysiological correlates in neuropsychiatric disorders: a review of human studies. Int. J. Psychophysiol. 97, 310-322. doi: 10.1016/j.ijpsycho.2014.10.013.The

Kayser, J., Tenke, C. E., Malaspina, D., Kroppmann, C. J., Schaller, J. D., Deptula, A., et al. (2010). Neuronal generator patterns of olfactory event-related brain potentials in schizophrenia. Psychophysiology 47, 1075-1086. doi: 10.1111/j. 1469-8986.2010.01013.x

Kirkpatrick, M. A. F., Combest, W., Newton, M., Teske, Y., Cavendish, J., McGee, R., et al. (2006). Combining olfaction and cognition measures to screen for mild cognitive impairment. Neuropsychiatr. Dis. Treat. 2, 565-570. doi: $10.2147 /$ nedt.2006.2.4.565

Kobal, G., and Hummel, T. (1998). Olfactory and intranasal trigeminal eventrelated potentials in anosmic patients. Laryngoscope 108, 1033-1035.

Krumm, S., Kivisaari, S. L., Probst, A., Monsch, A. U., Reinhardt, J., Ulmer, S., et al. (2016). Cortical thinning of parahippocampal subregions in very 
early Alzheimer's disease. Neurobiol. Aging 38, 188-196. doi: 10.1016/j. neurobiolaging.2015.11.001

Laskaris, N. A., Tarnanas, I., Tsolaki, M. N., Vlaikidis, N., and Karlovasitou, A. K. (2013). Improved detection of amnestic MCI by means of discriminative vector quantization of single-trial cognitive ERP responses. J. Neurosci. Methods 212, 344-354. doi: 10.1016/j.jneumeth.2012.10.014

Libon, D. J., Xie, S. X., Eppig, J., Wicas, G., Lamar, M., Lippa, C., et al. (2010). The heterogeneity of mild cognitive impairment: a neuropsychological analysis. J. Int. Neuropsychol. Soc. 16, 84-93. doi: 10.1017/S135561770 9990993

Lötsch, J., and Hummel, T. (2006). The clinical significance of electrophysiological measures of olfactory function. Behav. Brain Res. 170, 78-83. doi: 10.1016/j.bbr. 2006.02.013

Luck, S. J. (2005). An Introduction to the event-related potential technique. Monogr. Soc. Res. Child Dev. 78:388.

Manning, E. N., Barnes, J., Cash, D. M., Bartlett, J. W., Leung, K. K., Ourselin, S., et al. (2014). APOE $\varepsilon 4$ is associated with disproportionate progressive hippocampal atrophy in AD. PLoS One 9:e97608. doi: 10.1371/journal.pone. 0097608

Maris, E., and Oostenveld, R. (2007). Nonparametric statistical testing of EEG- and MEG-data. J. Neurosci. Methods 164, 177-190. doi: 10.1016/j.jneumeth.2007. 03.024

Masurkar, A. V., and Devanand, D. P. (2014). Olfactory dysfunction in the elderly: basic circuitry and alterations with normal aging and Alzheimer's disease. Curr. Geriatr. Rep. 3, 91-100. doi: 10.1007/s13670-014-0080-y

McKhann, G., Drachman, D., Folstein, M., Katzman, R., Price, D., and Stadlan, E. M. (1984). Clinical diagnosis of Alzheimer's disease: report of the NINCDSADRDA Work Group* under the auspices of department of health and human services task force on Alzheimer's disease. Neurology 34, 939-944. doi: 10.1212/ WNL.34.7.939

Mueller, S. G., Schuff, N., Yaffe, K., Madison, C., Miller, B., and Weiner, M. W. (2010). Hippocampal atrophy patterns in mild cognitive impairment and Alzheimer's disease. Hum. Brain Mapp. 31, 1339-1347. doi: 10.1002/hbm.20934

Musicco, M., Sorbi, S., Bonavita, V., Caltagirone, C., Aguglia, U., Burzomati, D., et al. (2004). Validation of the guidelines for the diagnosis of dementia and Alzheimer's disease of the Italian neurological society. Study in 72 Italian neurological centres and 1549 patients. Neurol. Sci. 25, 289-295. doi: 10.1007/ s10072-004-0356-7

Olichney, J. M., Taylor, J. R., Gatherwright, J., Salmon, D. P., Bressler, A. J., Kutas, M., et al. (2008). Patients with MCI and N400 or P600 abnormalities are at very high risk for conversion to dementia. Neurology 70, 1763-1770. doi: 10.1212/01.wnl.0000281689.28759.ab

Olofsson, J. K., Nordin, S., Wiens, S., Hedner, M., Nilsson, L. G., and Larsson, M. (2010). Odor identification impairment in carriers of ApoE-e\{open 4 is independent of clinical dementia. Neurobiol. Aging 31, 567-577. doi: 10.1016/j. neurobiolaging.2008.05.019

Pause, B. M., and Krauel, K. (2000). Chemosensory event-related potentials (CSERP) as a key to the psychology of odors. Int. J. Psychophysiol. 36, 105-122. doi: 10.1016/S0167-8760(99)00105-1

Pause, B. M., Sojka, B., and Ferstl, R. (1997). Central processing of odor concentration is a temporal phenomenon as revealed by chemosensory event-related potentials (CSERP). Chem. Senses 22, 9-26. doi: 10.1093/chemse/ 22.1.9

Pause, B. M., Sojka, B., Krauel, K., and Ferstl, R. (1996). The nature of the late positive complex within the olfactory event- related potential (OERP). Psychophysiology 33, 376-384. doi: 10.1111/j.1469-8986.1996. tb01062.x

Perrin, F., Pernier, J., Bertrand, O., and Echallier, J. F. (1989). Spherical splines for scalp potential and current density mapping. Electroencephalogr. Clin. Neurophysiol. 72, 184-187. doi: 10.1016/0013-4694(89)90180-6

Petersen, R. C. (2011). Mild cognitive impairment. N. Engl. J. Med. 364, 2227-2234. doi: 10.1056/NEJMcp0910237
Poellinger, A., Thomas, R., Lio, P., Lee, A., Makris, N., Rosen, B. R., et al. (2001). Activation and habituation in olfaction-an fMRI study. Neuroimage 13, 547-560. doi: 10.1006/nimg.2000.0713

Rami, L., Loy, C. T., Hailstone, J., and Warren, J. D. (2007). Odour identification in frontotemporal lobar degeneration. J. Neurol. 254, 431-435. doi: 10.1007/ s00415-006-0379-5

Roberts, R. O., Christianson, T. J. H., Kremers, W. K., Mielke, M. M., Machulda, M. M., Vassilaki, M., et al. (2016). Association between olfactory dysfunction and amnestic mild cognitive impairment and alzheimer disease dementia. JAMA Neurol. 73, 93-101. doi: 10.1001/jamaneurol.2015.2952

Saunders, N. L. J., and Summers, M. J. (2010). Attention and working memory deficits in mild cognitive impairment attention and working memory in MCI. J. Clin. Exp. Neuropsychol. 32, 350-357. doi: 10.1080/1380339090304 2379

Schriever, V. A., Góis-Eanes, M., Schuster, B., Huart, C., and Hummel, T. (2014). Olfactory event-related potentials in infants. J. Pediatr. 165, 372-375.e2. doi: 10.1016/j.jpeds.2014.04.033

Shi, F., Liu, B., Zhou, Y., Yu, C., and Jiang, T. (2009). Hippocampal volume and asymmetry in mild cognitive impairment and Alzheimer's disease: metaanalyses of MRI studies. Hippocampus 19, 1055-1064. doi: 10.1002/hipo.20573

Soudry, Y., Lemogne, C., Malinvaud, D., Consoli, S. M., and Bonfils, P. (2011). Olfactory system and emotion: common substrates. Eur. Ann. Otorhinolaryngol. Head Neck Dis. 128, 18-23. doi: 10.1016/j.anorl.2010.09.007

Squires, N. K., Squires, K. C., and Hillyard, S. A. (1975). Two varieties of long-latency positive waves evoked by unpredictable auditory stimuli in man. Electroencephalogr. Clin. Neurophysiol. 38, 387-401. doi: 10.1016/00134694(75)90263-1

Suk, H. I., and Shen, D. (2013). "Deep learning-based feature representation for $\mathrm{AD} / \mathrm{MCI}$ classification," in Medical Image Computing and Computer-Assisted Intervention - MICCAI 2013. MICCAI 2013. Lecture Notes in Computer Science, Vol. 8150, eds K. Mori, I. Sakuma, Y. Sato, C. Barillot, and N. Navab (Berlin: Springer), 583-590. doi: 10.1007/978-3-642-40763-5_72

Tampellini, D. (2015). Synaptic activity and Alzheimer's disease: a critical update. Front. Neurosci. 9:423. doi: 10.3389/fnins.2015.00423

van Deursen, J. A., Vuurman, E. F., Smits, L. L., Verhey, F. R., and Riedel, W. J. (2009). Response speed, contingent negative variation and P300 in Alzheimer's disease and MCI. Brain Cogn. 69, 592-599. doi: 10.1016/j.bandc.2008.12.007

Van Groen, T., and Wyss, J. M. (1990). Extrinsic projections from area CA1 of the rat hippocampus: olfactory, cortical, subcortical, and bilateral hippocampal formation projections. J. Comp. Neurol. 302, 515-528. doi: 10.1002/cne. 903020308

Wang, L., Walker, V. E., Sardi, H., Fraser, C., and Jacob, T. J. (2002). The correlation between physiological and psychological responses to odour stimulation in human subjects. Clin. Neurophysiol. 113, 542-551.

Wesson, D. W., Levy, E., Nixon, R. A., and Wilson, D. A. (2010). Olfactory dysfunction correlates with amyloid-beta burden in an Alzheimer's disease mouse model. J. Neurosci. 30, 505-514. doi: 10.1523/JNEUROSCI.4622-09. 2010

Yamagishi, M., Ishizuka, Y., and Seki, K. (1994). Pathology of olfactory mucosa in patients with Alzheimer's disease. Ann. Otol. Rhinol. Laryngol. 103, 421-427.

Conflict of Interest Statement: The authors declare that the research was conducted in the absence of any commercial or financial relationships that could be construed as a potential conflict of interest.

Copyright (c) 2018 Invitto, Piraino, Ciccarese, Carmillo, Caggiula, Trianni, Nicolardi, Di Nuovo and Balconi. This is an open-access article distributed under the terms of the Creative Commons Attribution License (CC BY). The use, distribution or reproduction in other forums is permitted, provided the original author(s) and the copyright owner(s) are credited and that the original publication in this journal is cited, in accordance with accepted academic practice. No use, distribution or reproduction is permitted which does not comply with these terms. 